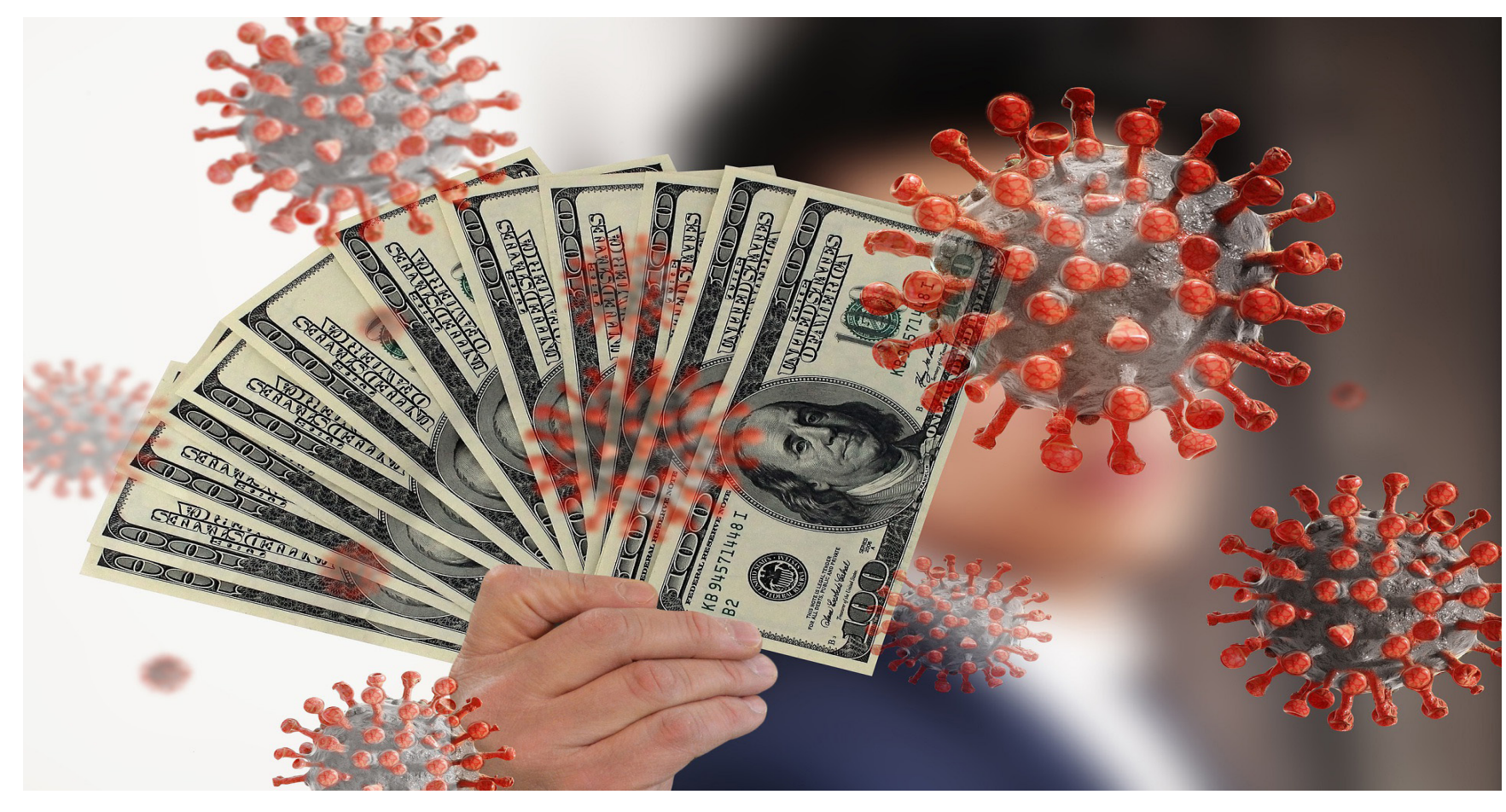

\title{
Impacto del coronavirus en el comercio internacional
}

\section{Impact of the coronavirus on international}

\section{Duban Contreras}

Estudiante, Fundación de Estudios Superiores Comfanorte, Cúcuta, Colombia
Yuri Ballena-Pérez

Estudiante, Fundación de Estudios Superiores Comfanorte, Cúcuta, Colombia 
Cómo citar: Contreras, D. Ballena-Pérez, Y. (2019). Impacto del coronavirus en el comercio internacional. Reflexiones contables (Cúcuta), 2 (2), 69-76.

\section{Resumen}

El principal objetico de este artículo, es dar a conocer cómo ha afectado la pandemia a las diferentes naciones, enfocándonos en sus economías, $Y$ el trabajo que están haciendo los países para no dejarse afectar durante este periodo. Teniendo en cuenta que muchos de estos, ya venían con una caída económica bastante preocupante y que apenas se estaban recuperando. El virus termino afectando su estabilidad financiera, dejándolos sin recursos para responder a esta enfermedad, sin mencionar que esto causo un cifra indescriptible de desempleo y en si el aumento de la pobreza. Lo cual ocasiono que tuvieran que tomar medidas drásticas para detener esta crisis, así mismo ir pensado en estrategias para recuperarse apenas pase esta ola de virus.

$\begin{array}{lrr}\text { Palabras } & \text { clave: } & \text { Comercio } \\ \text { internacional, } & \text { covid-19, } & \text { consecuencias. }\end{array}$

\section{Abstract}

The main objective of this article is to publicize how the pandemic has affected different nations, focusing on their economies, and the work that countries are doing to remain unaffected during this period. Considering that many of these countries were already in a very worrying economic downturn and were barely recovering. The virus ended up affecting their financial stability, leaving them without the resources to respond to this disease, not to mention that this caused an indescribable amount of unemployment and increased poverty. This caused them to have to take drastic measures to stop this crisis, as well as thinking of strategies to recover as soon as this wave of the virus passes.

Keywords: trade, covid-19,

International consequences. 


\section{Introducción}

Para que podamos entender la importancia del comercio internacional y en sí, como afecta el covid-19 a las diferentes naciones en término de desarrollo, primero tenemos que tener claro el valor que tiene este en los diferentes países.

El intercambio de bienes no es algo reciente, esto empezó con el trueque, el cual se hacía por la necesidad de obtener otros bienes por el mismo precio, a medida que iba avanzando el desarrollo, eso se fue desapareciendo y apareció la moneda la cual sirve para el intercambio de mercancías de diferentes estados. Más adelante se dejó de ver estos intercambios como una competencia y paso a ser un beneficio para los países, los cuales intercambiar sus riquezas, para un beneficio mutuo.

Hoy en día el comercio internacional, es muy importante, porque ayuda al desarrollo de un país, así mismo fomenta el empleo y el crecimiento de sus empresas, además sirve para que otros estados aumenten la oferta de bienes, también ayuda a adquirir materia prima de otras naciones y así tener variedad de productos.

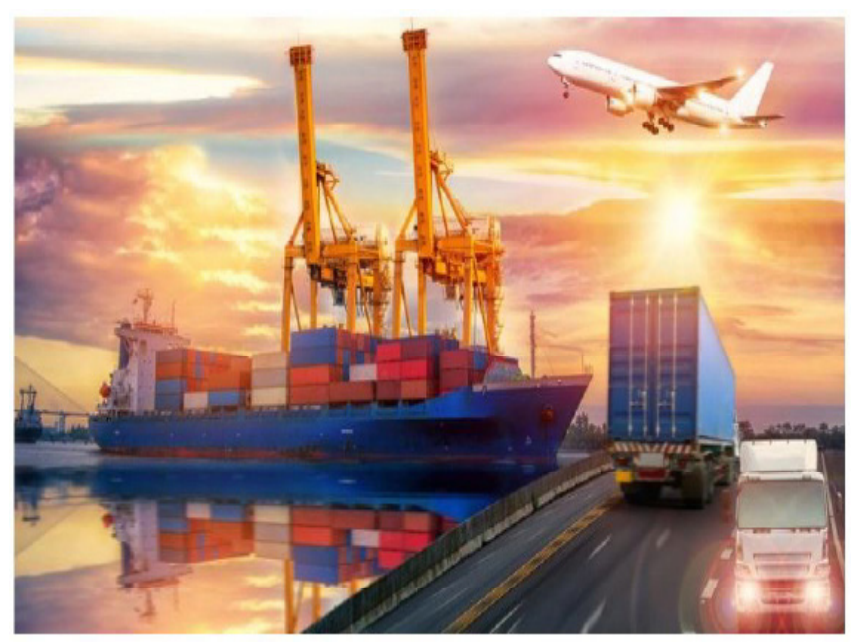

Recuperado de: shorturl.at/deszY

\section{Como ha afectado el covid-19 el comercio de los diferentes países}

Esta pandemia afecta a todos los países, tanto en sus importaciones como exportaciones. Pero les ha traído más consecuencia a los países pobres, ya que estos dependen de los demás, y al no poder importar, les trae efectos negativos a la economía del país. Los demás países luchan para no caer en crisis, aunque ha sido muy complicado, puesto que muchos dependían de las exportaciones de china u otros naciones, las cuales también han sido afectadas, porque les ha tocada suspender la cadena producción y algunas empresas les ha tocado cerrar, al no recibir los necesarios ingresos para mantenerla a flote.

Este virus además de ocasionar desastres en la economía de los diferentes países, puede llegar a causar una posible guerra de precios, por el petróleo crudo, pues la economía de muchos países depende de este recurso.

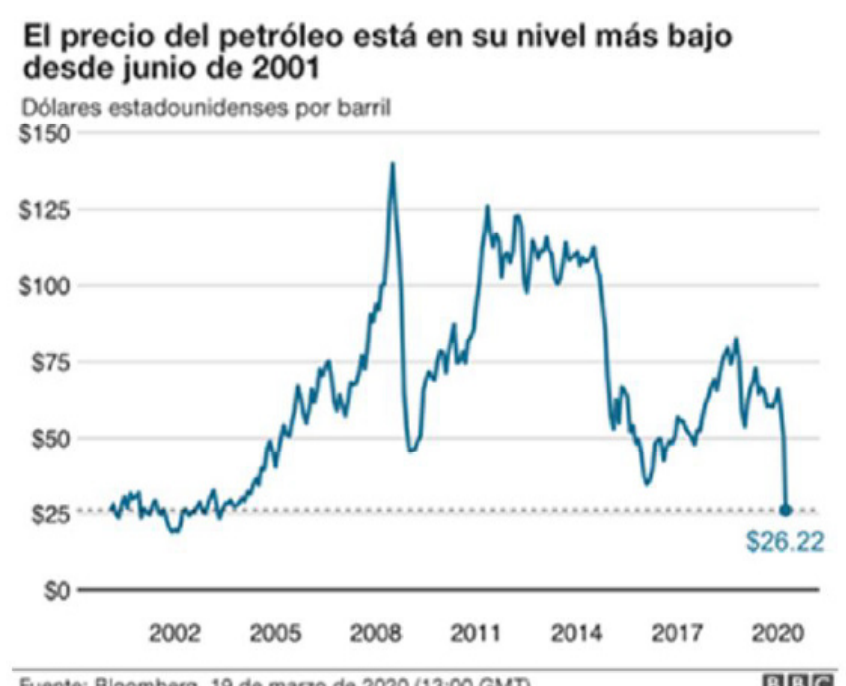

Fuente: Bloomberg. 19 de marzo de 2020 (13:00 GMT)

$\mathrm{BBC}$

Algunos países han optado por pedir ayuda a otras naciones, para no caer en crisis y mantener su comercio estable. De acuerdo Bárcena, (2020) "Ningún país podrá combatir esta pandemia sin la cooperación global y regional".

Según Bonomelli, (2020) "China, el epicentro de la pandemia y de las cadenas 


\section{2}

globales de valor, vio caer sus exportaciones en un 17 por ciento y sus importaciones un 4 por ciento en el primer bimestre del 2020, comparado con ese mismo período el año anterior. En Estados Unidos, las importaciones totales $y$ las provenientes de América Latina y el Caribe (ALC) también cayeron en enero, en un 4 por ciento y 2 por ciento en términos anuales, respectivamente, cuando apenas comenzaba la pandemia. En Brasil, las exportaciones del primer bimestre del año se redujeron un 8,5 por ciento, también en términos anuales. Estas cifras son alarmantes si se tiene en cuenta que el comercio mundial ya se encontraba en plena desaceleración: en2019 creció apenas 1 por ciento, comparado con un promedio de 5 por ciento en las últimas dos décadas".

Hay que tener en cuenta que los países dependen del comercio internacional, es decir: de los ingresos que reciben los estados principalmente por las exportaciones. De esta manera destacar, el acompañamiento de estos para el fortalecimiento de la economía.

Al afectar el comercio exterior, perjudica el balance que llevan las naciones para un buen funcionamiento.

\section{Los 7 países más afectados a causa del virus (covid-19)}

Estados unidos, esta entre uno de los primeros paises que ha sido mas afectado por el virus que se ha venido presentando, esto ha provocado el cierre de varios sectores economicos, los cuales eran muy importantes para la economia de este pais, tambien ha detendido la expansion record que llevaba estados unidos, y esto a causa del covid 19. De esta manera se aprobaron nuevas leyes para mejorar la eficacia de los programas incluidos en los tres paquetes fiscales los cuales son: la reserva federal; la cual redujo la tasa de interes hasta el limite inferior de cero, ofreció una expansión cuantitativa e limitada, y recurrió a distintos instrumentos de política, esto con el objetivo de mantener el funcionamiento de los mercados financieros. Teniendo en cuenta el periódico el tiempo. "La economía estadounidense cayó a un ritmo anual del $32,9 \%$ en el segundo trimestre de 2020 por los efectos de la pandemia del coronavirus, la mayor caída trimestral desde que se tienen registros, informó el Gobierno. Los analistas pronosticaron una caída del $35 \%$. El gasto de los consumidores, que supone dos tercios de la actividad económica en EE. UU., se contrajo un $34,6 \%$. El hundimiento trimestral coincide con las estrictas medidas de restricción de movilidad y de cierre de negocios para controlar la expansión del virus."

Perú, es el segundo país más afectado porque, es uno de los que lleva más meses en confinamiento y esto ha hecho que la economía se vea afectada seriamente, lo cual no le ha servido, ya que los contagios no han frenado en ningún momento, Perú esta denominado como la segunda nación que peor caída económica ha tenido en América Latina, por lo que este año la caída fue de un $12 \%$. El confinamiento causo un efecto negativo, ya que propicio el desempleo y al mismo tiempo se propago más el virus en este país. Según Zacarías, (2020) "El país andino lleva más de 100 días de confinamiento, y más de 2 millones de peruanos han perdido sus puestos de trabajo. El empleo informal, que hasta antes de la emergencia sanitaria era más del $72 \%$ podría llegar hasta un $80 \%$, según algunos analistas."

Argentina, es el tercero porque este país venía con una caída económica desde el año 2015, y con una deuda externa bastante preocupante, y al aparecer este virus lo golpeó fuertemente puesto que venía disminuyendo desde hace tiempo. El estado al acabar con todos los activos y pasivos, y adquirir deudas hasta el punto de agotar la capacidad de 
crédito, y destruir el patrimonio neto, al llegar la pandemia les fue imposible pedir préstamo para sostener esta emergencia. Como lo hace notar Hurtado, (2020)" la emergencia representa una amenaza especial para la economía argentina, cuyo crecimiento estuvo estancado en el gobierno de Mauricio Macri (2015 - 2019) e incluso en el último mandato de Cristina Fernández de Kirchner (20122015), según le aseguró a EL TIEMPO Ramiro Castiñeira, exasesor externo del Mercosur y economista de la consultora privada Econométrica." Este confinamiento hizo que la pobreza alcanzara $35,5 \%$ y una de las edades que están haciendo más afectadas es la de 14 años.

México, el cuarto de modo que su impacto es incomprensible, puesto que ha afectados los sectores productivos del país y en si ha causado desempleo, la inversiones también han sido afectadas, al ser un país que su principal ingresos lo recibe por el petróleo hace que este se vea más afectado. Este país literalmente está pasando por una crisis económica. Como afirma Carlos Heredia "En México ya estamos en una severa crisis económica; sus manifestaciones son el desplome de precios del petróleo, la caída en la actividad económica en 2019 y 2020, y el alza en la cotización del dólar."

Colombia, quinto país más afectados por este virus.Según un informe de la "universidad Sergio arboleda" puesto que esta pandemia ha hecho que el país haya tenido caídas en los mercados, también ha afectado los precios del petróleo, y los proyectos que tenían para el crecimiento a nivel global. La economía colombiana tuvo un desplome. Como expresa moreno, (2020) "Las actividades económicas que resultaron más golpeadas fueron comercio al por mayor y al por menor, reparación de vehículos automotores y motocicletas, transporte y almacenamiento, alojamiento y servicios de comida (que decreció 34,3\% y contribuye $-6,6$ puntos porcentuales a la variación anual); industrias manufactureras (que decreció 25,4\% y contribuye -3,1 puntos porcentuales a la variación anual), y construcción, que decreció 31,7\% y contribuye $-2,1$ puntos porcentuales a la variación anual)." Chile, sexto afectado en consecuencia de la pandemia. Esté apenas se estaba recuperando de una clase de protesta sociales, cuando aparece este virus, este hizo que aplazaran los planes futuros, pues ahora se tenían que empezar a preocupar era por mantener a salvo a la población, a pesar que los chilenos no tomaron decisiones drásticas respecto al confinamiento han tenido un desequilibrio económico. A consecuencia han pensado en un plan gastico de emergencia. "Dentro de las medidas comprendidas estaba la protección de empleo, inyección de liquidez a las empresas, complemento a los ingresos de las personas más afectadas y la entrega de un bono para el $60 \%$ de las familias más vulnerables pertenecientes al Registro Social de Hogares - facilidades para el pago de cuentas de servicios básicos como la luz o Internet. ".De acuerdo EFE, (2020).

Brasil, es el séptimo país afectado por la ola de la pandemia, al poseer este país una inestabilidad política con los cambios de ministros, y los conflictos entre ejecutivos y legislativos, esto hace que esta crisis empeore la situación, aparte la escases de trabajo se está elevando cada vez más, haciendo que en los siguientes meses se pueden perder una gran cantidad de puestos de trabajo, y esto va a causar que los brasileños acudan al seguro de desempleo. En opinión de lindar, (2020) "La incertidumbre política afecta también a la tasa cambiaria, según los economistas. El dólar estadounidense se disparó este año frente a muchas monedas, pero el real brasileño es una de las que más se ha devaluado, con una pérdida del 30 por ciento. Eso, pese a que el Banco Central estuvo constantemente vendiendo reservas en moneda extranjera." 


\section{4}

\section{DESEMPLEO EN LOS PAISES A CAUSA DEL COVID-19}

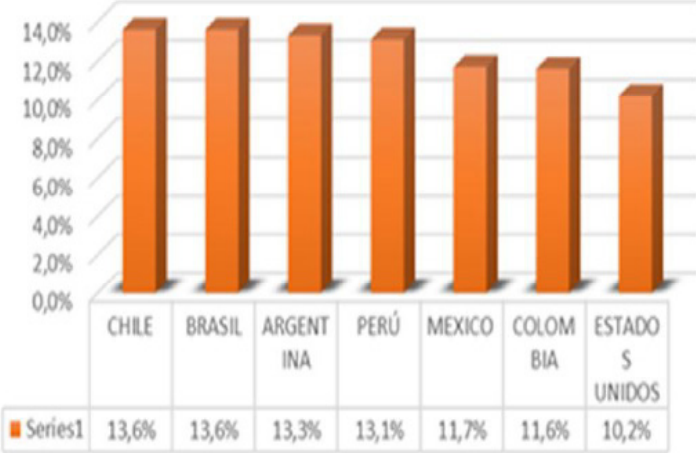

Cómo reactivar la economía durante el civil 19 (coronavirus)

Para volver a activar los mercados los países tienen que planificar unos objetivos con el fin de mejorar su economía, y al mismo tiempo buscar unas estrategias para que este virus no se propague más, según rubio, (2020) "Sobre cómo lograr los objetivos anteriores ya hay varios estudios como el que publicó recientemente McKinsey \& Company en el que se parte de que la crisis tiene tres fases: primera, suprimir el virus y apoyar a los afectados; segunda, reabrir la economía y contener el virus; y tercera, estabilizar, recuperar y transformar." Antes de pensar en volver a mejorar las finanzas de cada nación, los estados tienen que garantizar al ciudadano una protección de salud donde ellos puedan sentirse con una seguridad al realizar sus labores de trabajo, y esto con el objetivo de prevenir el número de contagios.

Al realizar estas tres etapas los gobiernos tiene que contar con un buen respaldo de ayuda médica muy profesional, con el fin de detectar a tiempo los posibles contagios que se estén generando alrededor de las áreas de trabajo y así poder contener o contrarrestar los ataques del civil 19 (coronavirus).

Las autoridades juegan un papel muy importante en los objetivos que se quieren plantear para mejorar la situación del país, donde deben mostrarse con liderazgo y solidez lo cual es dejar de depender que la solución es mantener a la ciudadanía en aislamiento, para lograr esto se debe desistir a esa idea permitiendo que el ciudadano pueda trabajar bajo un orden público, el cual se debe respetar y recibir la colaboración de la población para que esto se pueda llevar a cabo.

El último objetivo es acelerar las investigaciones para encontrar la cura a este virus, y así poder enfocarse en la recuperación de la economía lo cual se puede lograr implementando estrategias relacionadas con la salud. Para la reactivación es necesario mirar los sectores con más contagios y supervisar que se cumplan con los protocolos de seguridad. Es necesario tomar decisiones que fomente la responsabilidad de las personas lo cual se puede llevar a cabo por medio de campañas que promuevan la importancia de cuidarse para no permitir ser contagiados y así poder disminuir la propagación de este.

\section{Bancos centrales que recortaron tasas de interés para fortalecer sus economías}

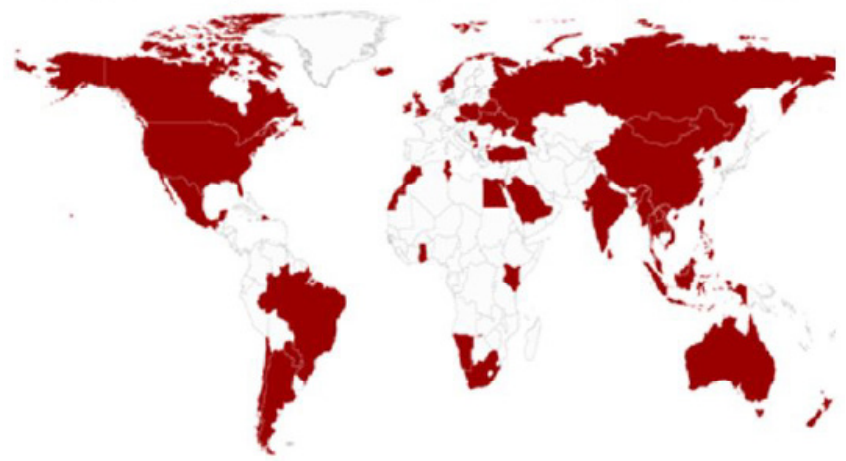

Fuente: Bloomberg, 19 de marzo de 2020 (15:00 GMT) BBC

Recuperado de: shorturl.at/epKMU 


\section{Conclusiones}

Pudimos observar que antes que apareciera el virus, algunos países ya estaban pasando por una situación económica bastante crítica y la aparición de este empeoro las cosas, pero las naciones no se dejan decaer tan fácilmente y están haciendo todo lo posible para mantener sus finanzas estables.

Se pudo identificar un porcentaje inesperado de desempleo en los deferentes estados, una de la causa es la pandemia, pero eso no es resiente, según las investigaciones que realizamos, eso viene desde años atrás. La economías de los diferente naciones están esperando que pase todo esto, para poder retomar todos los proyectos que tenían planteados para ayudar a las persona $y$ generar más empleo y en si ayudar a disminuir la pobreza. Para poder realizar todo lo que tienen planeado, los gobiernos tienen que planear nuevas estrategia, puesto que apenas pase esto no va a ser nada fácil poderse recuperar, para lograr lo que ellos quieren, les va a tomar un tiempo.

Las entidades van a necesitar cambiar su plan de trabajo, si no quieren cerrar sus negocios, ya que es necesario ir adaptándose a lo que estamos viviendo, puesto que no se sabe cuándo se va a acabar esta pandemia y si siguen esperando, eso le va a causar más consecuencia. Lo mejor que puedes hacer es innovar y hacer una planeación que ayude el desarrollo en medio de esta crisis.

Toca destacar que muchas ya lo están haciendo, tomaron este virus, como una ventaja para sacar adelante sus empresas.

\section{Referencias}

Bonelli, G. (2020). La pandemia del coronavirus y su impacto sobre el comercio internacional. Revista Integración y Cooperación Internacional, (30), 5-12. Recuperado de: https://revista-mici.unr. edu.ar/index.php/revistamici/article/view/45/30

Bonomelli, G. (2020). La pandemia del coronavirus y su impacto sobre el comercio internacional. Revista Integración y Cooperación Internacional, (30), 5-12.Recuperado de:https:// www.cepal.org/es/comunicados/covid-19tendra-graves-efectos-la-economia-mundialimpactara-paises-america-latina

Clavellina Miller, J. L. (2020). Posibles efectos del Coronavirus en la economía mundial. Recuperado de: http://bibliodigitalibd.senado. gob.mx/handle/123456789/4805

Quevedo-Barros, M. R., Vásquez-Lafebre, L. M., Quevedo-Vázquez, J. O., \& Pinzon-Prado, L. T. (2020). COVID-19 y sus efectos en el comercio internacional. Caso Ecuador. Dominio de las Ciencias, 6(3), 1006-1015. . Recuperado de: https:/www.dominiodelasciencias.com/ojs/ index.php/es/article/view/1330/html

El tiempo. (2020). Caída histórica de la economía de EE. UU. En segundo trimestre de 2020. Recuperado de: https://www.eltiempo.com/ mundo/eeuu-y-canada/cuanto-ha-caido-laeconomia-de-estados-unidos-durante-lapandemia-del-coronavirus-523990

France24. (2020). Perú padecerá la mayor caída económica en los últimos cien años. Recuperado de: https://www.france24.com/es/20200626peru-crisis-economica-pandemia-covid19coronavirus

El tiempo. (2020). Crisis del coronavirus amenaza con profundizar recesión en Argentina. Recuperado de: https://www.eltiempo. $\mathrm{com} / \mathrm{mundo} /$ latinoamerica/impacto-delcoronavirus-en-la-economia-argentina-486364

Fitz Asesores. (2020). ¿Cuál es el impacto del coronavirus en las finanzas mexicanas? .Recuperado de: https://fitzasesores.com/davidfitz/cual-es-el-impacto-del-coronavirus-en-las- 


\section{6}

finanzas-mexicanas/

El tiempo. (2020). Economía colombiana se desplomó 15,7 \% por cuenta de la pandemia. Recuperado de: https://www.eltiempo. com/economia/sectores/economia-decolombia-se-desplomo-por-la-pandemiade-coronavirus-529352

El Mercurio. (2020). COVID-19 golpea la economía de Chile cuando se recuperaba de las protestas. Recuperado de: https://ww2. elmercurio.com.ec/2020/04/01/covid-19golpea-la-economia-de-chile-cuando-serecuperaba-de-las-protestas/

Dw. (2020). Brasil se encamina a la peor crisis económica de su historia. Recuperado de: https://www.dw.com/ es/brasil-se-encamina-a-la-peorcris is - e c on \% C $3 \%$ B $3 \mathrm{mica}-\mathrm{de}-\mathrm{su}$ historia/a-53500282

Ciat. Política Fiscal y Recuperación Económica en tiempos de pandemia. Recuperado de: https://www.ciat.org/politica-fiscal-yrecuperacion-economica-en-tiempos-depandemia/

La Republica. (2020). Cómo reactivar la economía durante la pandemia en las tres etapas de la crisis. Recuperado de: https:// www.larepublica.co/globoeconomia/comoreactivar-la-economia-en-medio-de-lapandemia-durante-las-tres-etapas-de-lacrisis-2993415

Volca. (2020). ¿Qué es el comercio internacional y cuál es su importancia?. Recuperado de: https://volca.com/que-es-el-comerciointernacional-y-cual-es-su-importancia/

Transferencia.Tec. (2020). Ante la pandemia, ¿cómo podemos reactivar la economía? Recuperado de: https://transferencia.tec. mx/2020/06/30/como-podemos-reactivar-laeconomia/ 